\title{
Investigation of In-Vivo Neuropharmacological and In-Vitro Thrombolytic Activity \& Phytochemical Analysis of Ethanolic Extract of Argyria Captiformis Leaves
}

\author{
Saiful Islam*, Naymul Karim, Imam Hasan, Md Hossan Sakib, Md. Harun-Or- Rashid, \\ Sadequr Rahman, Masudur Rahman
}

Department of Pharmacy, International Islamic University Chittagong, Chittagong, Bangladesh

\section{Email address:}

saifuliiucpharmacy@gmail.com (S. Islam),naiemph@gmail.com (N. Karim), hasanrajbp@yahoo.com (I. Hasan), sakibiiucph@gmail.com (Md. H. Sakib), haruniiucph@gmail.com (Md. Harun-Or-Rashid), sadeqpharm@yahoo.com (S. Rahman), mamun2001@hotmail.com (M. Rahman)

\section{To cite this article:}

Saiful Islam, Naymul Karim, Imam Hasan, Md Hossan Sakib, Md. Harun-Or- Rashid, Sadequr Rahman, Masudur Rahman. Investigation of In-Vivo Neuropharmacological and In-Vitro Thrombolytic Activity \& Phytochemical Analysis of Ethanolic Extract of Argyria Captiformis Leaves. American Journal of Biomedical and Life Sciences. Vol. 3, No. 2, 2015, pp. 16-24. doi: 10.11648/j.ajbls.20150302.12

\begin{abstract}
Objectives: Investigation with the crude ethanolic extract of Argyria captiformis leaves was carried out to evaluate its possible thrombolysis and to analyze in -vivo neuro-pharmacological effects as anxiety is a particular form of behavioral inhibition that occurs in response to novel environment events and also phytochemical screening of plant extract. Method: Ethanolic extract of Argyria captiformis Leaves was assessed for sedative and anxiolytic activity on Swiss albino mice and Thrombolytic activity was assessed with human blood and also phytochemical screening test was done by various chemical reagents. Sedative activity was evaluated by using hole cross, open field, thiopental sodium-induced sleeping time and anxiolytic property was evaluated by elevated-plus maze(EPM) tests at $400 \mathrm{mg} / \mathrm{kg}$ while the peripheral and thrombolytic activity determined by percentage of clot lysis. Result: In anxiolytic study, the extract displayed increased percentage of entry into open arm at the dose of $400 \mathrm{mg} / \mathrm{kg}$. The extract produced a significant $(\mathrm{P}<0.01)$ increase in sleeping duration and reduction of onset of sleep compared to sodium thiopental at doses $(400 \mathrm{mg} / \mathrm{kg})$. The extract $(400 \mathrm{mg} / \mathrm{kg})$ also showed suppression of motor activity and exploratory activity of the mice in both open field and hole cross test. Argyria captiformis alone \& Argyria captiformis in combination with Streptokinase demonstrated $38.19 \pm 4.76 \%$ \& $77.45 \pm 2.97 \%$ clot lysis effect respectively \& revealed significant with comparison to both the control agent. The presence of tannins, glycosides, saponins, flavonoids, cardiac glycosides, and phytosterols was determined. Conclusion: The pharmacological profiles of the present investigation of the ethanol extract of $A$. captiformis indicate that the extract possess good CNS depressant and exhibited considerable thrombolytic as it significantly reduced locomotion, onset of sleep, increased duration of sleep and also presence of, glycosides, cardiac glycosides, saponins, flavonoids ,tannins and phytosterols.
\end{abstract}

Keywords: Sedative and Anxiolytic Activity, Phytochemical, Argyria Captiformis, Thrombolytic Activity, \% Lysis of Clot

\section{Introduction}

Anxiety and depression are the most common psychiatric disorders. Over $20 \%$ of the adult population suffers from these illnesses at some time during their lives ${ }^{[1-3]}$. It has become an important area of research interest in psychopharmacology during this decade ${ }^{[4]}$.

Benzodiazepines are among the most prescribed and effective antianxiety drugs used worldwide ${ }^{[5] \text {. }}$

But these are being slowly replaced by antidepressants, which are not only efficacious in depression, but also in the acute and long-term Treatment of several anxiety disorders ${ }^{[6]}$.

Consumption of these drugs is believed to double every five years ${ }^{[7]}$ Most of these drugs, however, have an unfavorable risk and benefit ratio, and their prominent side effects still represent a barrier to long-term treatment with these drugs ${ }^{[8]}$. In addition, the risk of interaction with other substances is high, particularly with alcohol ${ }^{[9]}$. Hence, there is an urgent need to search for newer, better-tolerated, and more efficacious therapeutic agents, for better management of anxiety and depression. 
However, so far, its effect on central nervous activity has not been studied. Therefore; we undertook the study to evaluate the anxiolytic potential of $A$. Captiformis by using different animal models and studying the effect of the plant on their exploratory behavior.

One of the major causes of blood circulation problem is the formation of blood clots. Thrombi or emboli can lodge in a blood vessel and block the flow of blood in that location depriving tissues of normal blood flow and oxygen. This can result in damage, destruction (infarction), or even death of the tissues (necrosis) in that area ${ }^{[10]}$.A blood clot (thrombus) is formed from fibrinogen by thrombin and is lysed by plasmin, which is activated from plasminogen by tissue plasminogen activator (tPA). Fribrinolytic drugs has been used to dissolve thrombi in acutely occluded coronary arteries there by to restore blood supply to ischaemic myocardium, to limit necrosis and to improve prognosis ${ }^{[11]}$.

Streptokinase is an antigenic thrombolytic agent used for the treatment of acute myocardial infarction. It reduces mortality as effectively as the nonantigenic altreplase in most infarct patients while having the advantages of being much less expensive. Tissue-type Plasminogen activator (tPA) is generally preferred as being effective and safer than either urokinase or streptokinase type activators. All available thrombolytic agents still have significant shortcomings, including the need for large doses to be maximally effective, limited fibrin specificity and a significant associated bleeding tendency. Because of the shortcomings of the available thrombolytic drugs, attempts are underway to develop improved recombinant variants of these drugs ${ }^{[12-16]}$.

The plant kingdom represents an enormous reservoir of biologically active compounds with various chemical structures and protective/disease preventive properties (phytochemicals). Nearly $50 \%$ of drugs used in medicine are of plant origin, and only a small fraction of plants with medicinal activity has been assayed. Therefore much current research devoted to the phytochemical investigation of higher plants which have ethnobotanical information associated with them. The phytochemicals isolated are then screened for different types of biological activity like thrombolytic potentials ${ }^{[17]}$. Herbal preparations are used potential source of medicine since ancient times to maintain health and regain healthy state of mind. Herbs showing thrombolytic activity have been studied and some significant observations have been reported ${ }^{[18]}$.

Argyria captiformis (Poir.) Ooster is a medicinal plants group is Dicot, Family is Convolvulaceae-Morning-glory family and growth habit is climber.

It is a large climber with milky juice, branches hispid. Leaves 7-13 cm long, ovate to orbicular, rarely oblonglanceolate, base shallowly to deeply cordate, suddenly short acuminate, sparsely hispid on both sides. Inflorescence of dense, capitate cymes in the axils of the leaves, on long peduncles. Bracts and sepals bristle-hispid. Flowers $3-4 \mathrm{~cm}$ long, redfish-purple or pink. Fruit globose, orange to reddish. It is widely distributed in Chittagong, Chittagong Hill Tracts, Cox's Bazar, Mymensingh, Moulvi bazaar, Rangpur,
Noakhali, Sylhet, Dhaka, in marginal forests and village thickets of Bangladesh ${ }^{[19]}$.A leaf paste is applied to affected areas to treat bruising on the legs (Chakma) ${ }^{[20]}$.Leaf-ash is used in eruption at the junction of ear pinnae.

\section{Material and Methods}

\subsection{Collection of Plant Material}

For investigation of Argyria captiformis leaves were collected from Naekangchori Upozilla, Bandarban District, Chittagong Division, Bangladesh during the month of April 2013.After that taxonomy confirmed by an expert of botany and plant Herbarium specialist Dr.Sheikh Bokhtear Uddin, Associate professor, Department of Botany, University of Chittagong. Chittagong, Bangladesh. The leaves of Argyria captiformis were collected at their fully mature form, from Chittagong hill Tract. After cleaning, the collected plant leaves were shade dried for twenty days in the low temperature and pulverized into a coarse powder using a suitable grinder. The powder was stored in an airtight container and kept in a cool, dark, and dry place until further analysis.

\subsection{Animals}

Swiss-albino mice (both sexes) weighing between (18-25 g)was used for the present study collected from International Centre for Diarrheal Diseases and Research, Bangladesh (ICDDR, B), Dhaka, Bangladesh. After their purchase, the mice's were kept in standard environmental conditions (24.0 $\pm 0^{\circ} \mathrm{C} \& 55-65 \%$ relative humidity and $12 \mathrm{~h}$ light/dark cycle) for one week to acclimate and fed ICDDRB formulated rodent food and water ad libitum. Guidelines of Institutional Animal Ethics Committee were followed to carry out this study.

\subsection{Drug and Chemicals}

The drugs and chemicals used for the experiments were diazepam (Square Pharmaceutical Ltd;Bangladesh), thiopental sodium (Gonoshastho Pharmaceuticals Ltd; Bangladesh), ethanol (Sigma Chemicals Co; USA).For Thrombolytic activity commercially available lyophilized Streptokinase (SK) vials (Polamin Werk GmbH, Herdecke, Germany) of 1500000 IU was used as positive control. All other chemicals were of analytical grade.

\subsection{Extraction Process}

Approximately (620 gm.) powdered material was placed in clean flat bottomed glass container and soaked in 1.5 liter ethanol. The container with its content was sealed and kept for 15 days accompanied with occasional shaking and stirring for maximum wetting and extraction. The entire mixture was coarse filtration by piece of clean white cotton materials. Then the extract was filtered through whatman filter paper (Bibby RE200, Sterilin Ltd; UK) and was concentrated to obtain ethanol crude extract and evaporated to dry using 
water bath .Then the extract was stored at $4{ }^{\circ} \mathrm{C}$ until used.

The study was performed to find out if the extract had any effect on central nervous system. Elevated plus maze test was conducted for determination of anxiolytic activity whereas thiopental sodium induced sleeping time test was for sedative activity. Effect on exploratory behavior of mice was evaluated by hole cross test and open field test.

\subsection{Anxiolytic Activity}

In elevated plus maze test, the apparatus was made of wood with two open and two closed arms across each other respectively forming a plus-sign figure. The elevated plus maze $(\mathrm{EPM} ; 30 \mathrm{~cm} \times 6 \mathrm{~cm} \times 6 \mathrm{~cm}$, each arm) was situated 50 $\mathrm{cm}$ above the floor. After administration of the drug, each animal was placed at the center of the maze facing one of the closed arms. The number of open and closed arm entries, plus time spent in open and closed arms was recorded for 5 min at $0,30,60,90,120 \mathrm{~min}$ after administration of the extract $(400 \mathrm{mg} / \mathrm{kg})$, diazepam $(1 \mathrm{mg} / \mathrm{kg})$ and vehicle $(1 \%$ Tween 80 in water). The whole test was carried out in a sound attenuated room ${ }^{[21]}$. Entry into an arm was defined as the point when the animal placed all four paws onto the arm.

$$
\begin{aligned}
& \text { Percent of time spent in arm } \\
& =\frac{\text { Time in open arm }}{\text { Time in open arm }+ \text { Time in closed arm }}
\end{aligned}
$$

This test has been widely validated for measuring anxiolytic- and anxiogenic-like activities in rodents ${ }^{[22,23]}$.

\subsection{Sedative Activity}

For the experiment, the animals were randomly assigned to four groups, each with 5 mice. The test groups were given the leaf extract of $A$. captiformis at doses of $400 \mathrm{mg} / \mathrm{kg}$ body weight, while the positive control was treated with diazepam $(1 \mathrm{mg} / \mathrm{kg})$ and control group with vehicle (1\% Tween 80 in water).Thirty minutes later, thiopental sodium $(40 \mathrm{mg} / \mathrm{kg})$ was administered to each mouse to induce sleep. The animals were observed by placing them on separate chambers for the latent period (time between thiopental administrations to loss of righting reflex) and duration of sleep i.e. time between the loss and recovery of righting reflex. The onset of sleep and total sleeping time were recorded for control, positive control and test groups ${ }^{[24]}$.

\subsection{Exploratory Activity}

\subsubsection{Open Field Test}

The method was adopted as described by Gupta et al [24]. In open field test, the animals were divided into control, positive control and test groups containing 5 mice each. The test groups received extract of $A$. captiformis at the doses of $400 \mathrm{mg} / \mathrm{kg}$ body weight orally whereas control group received vehicle (1\% Tween 80 in water). The floor of half square meter open field was divided into a series of squares each alternatively colored black and white. The apparatus had a $40 \mathrm{~cm}$ height wall. The number of squares traveled by the animals was counted for $5 \mathrm{~min}$ at $0,30,60,90,120 \mathrm{~min}$ after oral administration of doses of the extract.

\subsubsection{Hole Cross Test}

The apparatus was a cage of $30 \mathrm{~cm} \times 20 \mathrm{~cm} \times 14 \mathrm{~cm}$ with a steel partition fixed in the middle, dividing the cage into two chambers. A hole of $3.5 \mathrm{~cm}$ diameter was made at a height of $7.5 \mathrm{~cm}$ in the center of the cage. Animals were randomly divided into control, positive control and test groups containing 5 mice each. The test groups were treated with extract of $A$. captiformis at the dose of $400 \mathrm{mg} / \mathrm{kg}$ body weight orally whereas positive control group with diazepam $(1 \mathrm{mg} / \mathrm{kg})$ and control group with vehicle $(1 \%$ Tween 80 in water). Number of passages of the animals through the hole from one chamber to the other was counted for $5 \mathrm{~min}$ at 0,30 , 60,90 and 120 min after oral administration of the extract as well as diazepam and vehicle ${ }^{[25]}$. The apparatus was thoroughly cleaned after each trial.

\subsection{Statistical Analysis}

The data were expressed as mean \pm standard error of mean (S.E.M.). Statistical comparisons were performed using One way ANNOVA followed by Dennett's multiple comparison tests. The values obtained were compared with the vehicle control group and were considered statistically significant when $\mathrm{P}<0.05$.

\subsection{Preparation of Extract Solution for Thrombolytic Test}

$10 \mathrm{mg}$ of the extract was suspended in $10 \mathrm{ml}$ distilled water and shaken vigorously on a vortex mixer. Then the suspension was kept overnight and decanted to remove the soluble supernatant, which was filtered through a filter paper (Whatman No. 1). The solution was then ready for in vitro evaluation of clot lysis activity ${ }^{[26]}$.

\subsection{Streptokinase (SK) Solution Preparation}

To the commercially available lyophilized SK vial (Polamin Werk GmbH, Herdecke, Germany) of 15, 00,000 I.U., $5 \mathrm{ml}$ sterile distilled water was added and mixed properly. This suspension was used as a stock from which $100 \mu \mathrm{l}\left(30,000\right.$ I.U) was used for in vitro thrombolysis ${ }^{[26]}$.

\subsection{Specimen for Thrombolytic Test}

Whole blood $(5 \mathrm{ml})$ was drawn from healthy human volunteers $(n=10)$ without a history of oral contraceptive or anticoagulant therapy (using a protocol approved by the Ethics Committee of Pharmacy Department, International Islamic University Chittagong (approval no. ECPDIIUC2013/03)500 $\mu 1$ of blood was transferred to each of the ten previously weighed Eppendorf tubes to form clots [26].

\subsection{Test Procedure for Thrombolytic Test}

Experiments for clot lysis were carried as reported earlier ${ }^{[26]}$.Venous blood drawn from healthy volunteers was transferred in different pre-weighed sterile Eppendorf tube 
(500 $\mu \mathrm{l} /$ tube) and incubated at $37^{\circ} \mathrm{C}$ for 45 minutes. After clot formation, serum was completely removed (aspirated out without disturbing the clot formed). Each tube having clot was again weighed to determine the clot weight (Clot weight $=$ weight of clot containing tube - weight of tube alone).

Each eppendorf tube containing clot was properly labeled and $100 \mu \mathrm{l}$ of plant extract was added to the tubes. All the tubes were then incubated at $37^{\circ} \mathrm{C}$ for 90 minutes and observed for clot lysis. After incubation, fluid obtained was removed and tubes were again weighed to observe the difference in weight after clot disruption. Difference obtained in weight taken before and after clot lysis was expressed as percentage of clot lysis. Streptokinase and water were used as a positive and negative (non thrombolytic) control respectively. The experiment was repeated several times with the blood samples of different volunteers.

$\%$ clot lysis $=($ Weight of the lysis clot $/$ Weight of clot before lysis) $\times 10$

\subsection{Statistical Analysis}

The significance between \% clot lysis by herbal extract by means of weight difference was tested by the paired ttest analysis. Data are expressed as mean \pm standard deviation.

\subsection{Phytochemical Identification Tests Procedure}

The tests were done to find the presence of the active chemical constituents such as alkaloids, glycosides, resin, flavonoids, carbohydrates etc.

Phytochemical screening: Phytochemical examinations were carried out for all the extracts as per the standard methods ${ }^{[27]}$.

\subsection{Detection of Alkaloids}

Extracts were dissolved individually in dilute Hydrochloric acid and filtrate [27].

A) Mayer's Test: Filtrates were treated with Mayer's reagent (Potassium Mercuric Iodide). Formation of a yellow colored precipitate indicates the presence of alkaloids.

B) Wagner's Test: Filtrates were treated with Wagner's reagent (Iodine in Potassium Iodide).Formation of brown/reddish precipitate indicates the presence of alkaloids

C) Dragendroff's Test: Filtrates were treated with Dragendroff's reagent (solution of Potassium Bismuth Iodide). Formation of red precipitate indicates the presence of alkaloids.

D) Hager's Test: Filtrates were treated with Hager's reagent (saturated picric acid solution). Presence of alkaloids confirmed by the formation of yellow colored precipitate.

\subsection{Detection of Carbohydrates}

Extracts were dissolved individually in $5 \mathrm{ml}$ distilled water and filtered. The filtrates were used to test for the presence of carbohydrates ${ }^{[27]}$.

A) Molisch's Test: Filtrates were treated with 2 drops of alcoholic $\alpha$-naphthol solution in a test tube. Formation of the violet ring at the junction indicates the presence of Carbohydrates.

B) Benedict's Test: Filtrates were treated with Benedict's reagent and heated gently. Orange red precipitate indicates the presence of reducing sugars.

C) Fehling's Test: Filtrates were hydrolysed with dil. $\mathrm{HCl}$, neutralized with alkali and heated with Fehling's A \& B solutions. Formation of red precipitate indicates the presence of reducing sugars.

\subsection{Detection of Glycosides}

Extracts were hydrolysed with dil. $\mathrm{HCl}$, and then subjected to test glycosides ${ }^{[27]}$.

Legal's Test: Extracts were treated with sodium nitropruside in pyridine and sodium hydroxide. Formation of pink to blood red color indicates the presence of cardiac glycosides.

\subsection{Detection of Saponins ${ }^{[27]}$}

A) Froth Test: Extracts were diluted with distilled water to $20 \mathrm{ml}$ and this was shaken in a graduated cylinder for 15 minutes. Formation of $1 \mathrm{~cm}$ layer of foam indicates the presence of saponins.

B) Foam Test: $0.5 \mathrm{gm}$ of extract was shaken with $2 \mathrm{ml}$ of water. If foam produced persists for ten minutes it indicates the presence of saponins.

\subsection{Detection of Phytosterols ${ }^{[27]}$}

A) Salkowski's Test: Extracts were treated with chloroform and filtered. The filtrates were treated with few drops of Conc. Sulphuric acid, shaken and allowed to stand. Appearance of golden yellow color indicates the presence of triterpenes.

B) Libermann Burchard's test: Extracts were treated with chloroform and filtered. The filtrates were treated with few drops of brown ring at the junction indicates the presence of phytosterols.

\subsection{Detection of Phenols ${ }^{\text {[27] }}$}

Ferric Chloride Test: Extracts were treated with $3-4$ drops of ferric chloride solution. Formation of bluish black color indicates the presence of phenols.

\subsection{Detection of Tannins ${ }^{[27]}$}

Gelatin Test: To the extract, $1 \%$ gelatin solution containing sodium chloride was added. Formation of white precipitate indicates the presence of tannins.

\subsection{Detection of Flavonoids ${ }^{\text {[27] }}$}

A) Alkaline Reagent Test: Extracts were treated with few drops of sodium hydroxide solution. Formation of intense yellow color, which becomes colorless on addition of dilute acid, indicates the presence of flavonoids.

B) Lead acetate Test: Extracts were treated with few drops of lead acetate solution. Formation of yellow color 
precipitate indicates the presence of flavonoids.

\subsection{Detection of Proteins and Amino Acids ${ }^{\text {[27] }}$}

A) Xanthoproteic Test: The extracts were treated with few drops of conc. Nitric acid. Formation of yellow color indicates the presence of proteins

B) Ninhydrin Test: To the extract, $0.25 \% \mathrm{w} / \mathrm{v}$ ninhydrin reagent was added and boiled for few minutes. Formation of blue color indicates the presence of amino acid.

\subsection{Test for Terpennoids (Salkoski Test)}

Five $(1 \mathrm{mg} / \mathrm{ml})$ of each extract was mixed in $2 \mathrm{ml}$ of chloroform, and then $3 \mathrm{ml}$ concentrated $\mathrm{H}_{2} \mathrm{SO} 4$ was carefully added to form a layer. A reddish brown coloration of the interface was formed which showed positive results for the presence of terpenoids ${ }^{[28]}$.

\subsection{Anthraquinone Detection}

$200 \mathrm{mg}$ of each plant fraction was boiled with $6 \mathrm{ml}$ of $1 \%$ $\mathrm{HCl}$ and filtered. The filtrate was shaken with $5 \mathrm{ml}$ of benzene. The layer was removed and then $10 \% \mathrm{NH}_{4} \mathrm{OH}$ was added. Formation of pink, violet or red color in alkaline phase was observed for the presence of anthraquinone ${ }^{[28]}$.

\subsection{Identification of Phlobatinins}

For identification of Phlobatinins $80 \mathrm{mg}$ of each plant extract was boiled in $1 \%$ aqueous Hydrochloric acid, the deposition of a red precipitate indicates the presence of Phlobatinins ${ }^{[28]}$.

\subsection{Cardiac Glycosides Determination (Keller-Killani Test)}

Five $\mathrm{ml}$ of each extracts was treated with $2 \mathrm{ml}$ of glacial acetic acid containing one drop of ferric chloride solution. This was under with $1 \mathrm{ml}$ of concentrated sulphuric acid. A brown ring of the interface indicates a deoxysugar characteristic of cardenolides. A violet ring may appear below the brown ring, while in the acetic acid layer, a greenish ring may form gradually through thin layer ${ }^{[28]}$.

\section{Result}

In the EPM, the behavior of mice model, as observed, confirmed the anxiolytic activity of diazepam as reported previously. The ethanol extract. Of A.captiformis at the dose of $400 \mathrm{mg} / \mathrm{kg} \quad(\mathrm{P}<0.05)$, significantly increased the percentage of entries of mice into the open arms, and the percentage of time spent in the open arms of the EPM as shown in Table1. The number of closed arm entries and time spent in the closed arms were decreased significantly in the extract treated groups which was comparable with the standard diazepam.

Table 1. Effect of ethanolic extract of A. Captiformis on EPM test during 5 min test session.

\begin{tabular}{lllll}
\hline Group & Treatment & Dose, Route & \% Entry into open arm & \%of time (in seconds) spent in open arm \\
Control & $1 \%$ tween 80 in water & $10 \mathrm{ml} / \mathrm{kg}, \mathrm{p} . \mathrm{o}$ & $54.61 \pm 5.044$ & $58.33 \pm 1.527$ \\
Standard & Diazepam & $10 \mathrm{mg} / \mathrm{kg}, \mathrm{p} . \mathrm{o}$ & $77.14 \pm 4.95^{* *}$ & $79.33 \pm 1.52^{*}$ \\
Test & Extract & $10 \mathrm{mg} / \mathrm{kg}, \mathrm{p} . \mathrm{o}$ & $60.61 \pm 2.15^{*}$ & $62.67 \pm 0.577^{*}$ \\
\hline
\end{tabular}

Values are expressed as mean \pm S.E.M., $(\mathrm{n}=5) ; * \mathrm{P}<0.05, * * \mathrm{P}<0.01$, Dunnet test as compared to control (Vehicle $=0.4 \mathrm{~mL} / \mathrm{mouse})$

Table 2. The effect of the ethanolic extract of A. captiformis on sodium thiopental induced hypnosis in mice.

\begin{tabular}{lll}
\hline Groups & Onset of Sleep ( min) & Duration of Sleep (min) \\
\hline Control & $40.53 \pm 0.577$ & $47.00 \pm 1.000$ \\
Diazepam & $14.82 \pm 0.025^{* *}$ & $149.87 \pm 0.115^{* *}$ \\
Extract $400 \mathrm{mg} / \mathrm{kg}$ & $25.33 \pm 1.52^{* *}$ & $127.67 \pm 8.621^{* *}$ \\
\hline
\end{tabular}

Values are expressed as mean \pm S.E.M., $(\mathrm{n}=5) ; * \mathrm{P}<0.05, * * \mathrm{P}<0.01$, Dunnet test as compared to control (Vehicle $=0.4 \mathrm{~mL} /$ mouse).

In the thiopental induced hypnosis test, the extract at dose, $400 \mathrm{mg} / \mathrm{kg}$ showed a significant reduction in the time of onset of sleep and increased the duration of sleep. (Table 2). The effect of the extract $(400 \mathrm{mg} / \mathrm{kg})$ on the onset of sleep and the duration of sleep were comparable to that of standard. Doses of the extract potentiated the duration of thiopental sodium induced sleeping time in test animals compared to controls (Table 2).

Open field test of $A$. captiformis treated groups (400 mg/ $\mathrm{kg}$ body weight) showed significant reduction of movement from its initial value at 0 to $120 \mathrm{~min}$ (Figure 1). The number of squares traveled by the mice was decreased significantly from its initial value at 0 to $90 \mathrm{~min}$ at the dose level of 400 $\mathrm{mg} / \mathrm{kg}$ body weight $(\mathrm{P}<0.01)$ of the ethanol extract from the leaves of $A$. captiformis (Figure 1).

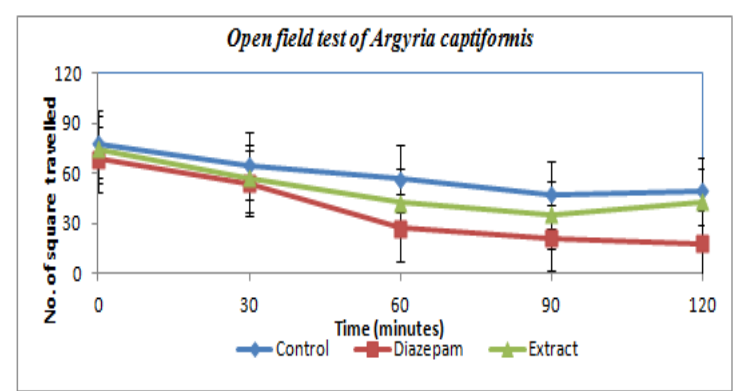

Figure 1. Effect of ethanolic extract of A. captiformis on exploratory behaviour Open field test in mice.

Values are mean \pm S.E.M, $(\mathrm{n}=5) ; * \mathrm{P}<0.05, * * \mathrm{P}<0.01$, Dunnet test as compared to Control (Vehicle $=0.4 \mathrm{~mL} /$ mouse).

The number of hole crossed from one chamber to another by mice of the control group was similar from 30 to $120 \mathrm{~min}$ (Figure 2). Hole cross test of A. captiformis treated groups showed decrease of movement from its initial value at 0 to 90 min. But, at doses of $400 \mathrm{mg} / \mathrm{kg} \quad(\mathrm{P}<0.01)$, maximum suppression of locomotors activity was displayed which was comparable to the reference drug diazepam (Figure 2). 


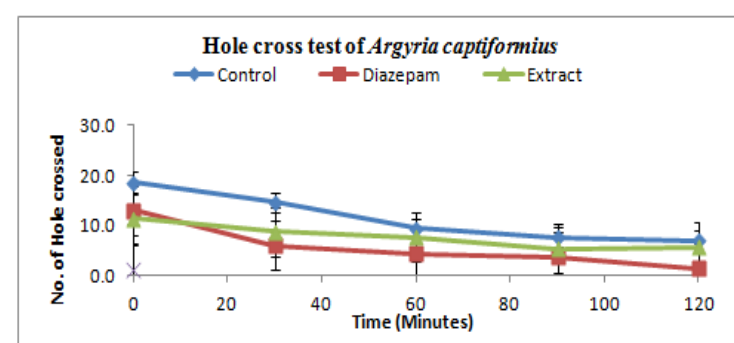

Figure 2. Effect of ethanolic extract of A. captiformis on exploratory behaviour (hole cross test).

Values are mean \pm S.E.M, $(\mathrm{n}=5) ; * \mathrm{P}<0.05, * * \mathrm{P}<0.01$, Dunnet test as compared to control (Vehicle $=0.4 \mathrm{~mL} /$ mouse).

Addition of $100 \mu \mathrm{l}$ SK, a positive control (30,000 I.U.) to the clots along with 90 minutes of incubation at $37^{\circ} \mathrm{C}$, showed $75.01 \pm 3.20 \%$ clot lysis. Clots when treated with $100 \mu 1$ sterile distilled water (negative control) showed only negligible clot lysis $(6.42 \%)$. The mean difference in clot lysis percentage between positive and negative control was very significant ( $\mathrm{p}$ value $<0.0001$ ). The in vitro thrombolytic activity study revealed that Argyria captiformis showed $38.19 \pm 4.76 \%$ clot lysis and Argyria captiformis in combination with Streptokinase showed $77.45 \pm 2.97 \%$ clot lysis activity. Percent clot lysis obtained after treating clots with herb and appropriate controls is shown in Figure 3. Statistical representation of the effective clot lysis percentage by our herbal preparation, positive thrombolytic control (Streptokinase) and negative control (sterile distilled water) is tabulated in Table 3.

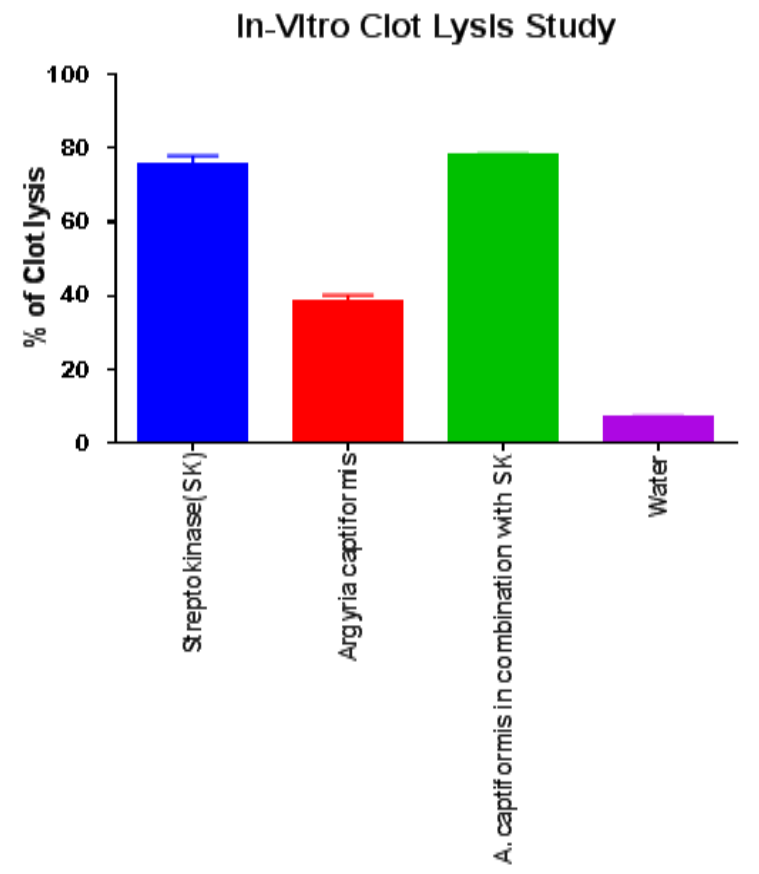

Figure 3. Clot lysis by Streptokinase, Argyria captiformis in combination with Streptokinase and Water.

Table 3. Effect of ethanolic extract of Argyria captiformis leaves \& Streptokinase (Positive control) on in vitro clot lysis.

\begin{tabular}{llll}
\hline Herb/Drug & Mean \pm S.D. (Clot Lysis \%) & t- value & P value(Two-tailed) when compared to negative control (Water) \\
\hline Streptokinase & $75.01 \pm 3.20$ & 68.86 & $<0.0001$ \\
Argyria captiformis & $38.19 \pm 4.76$ & 22.24 & $<0.0001$ \\
Combination of Argyria captiformis\& & $77.45 \pm 2.97$ & 71.04 & $<0.0001$ \\
Streptokinase & & \\
\hline
\end{tabular}

Statistical representation of the effective clot lysis percentage by herbal preparation's, positive thrombolytic control (Streptokinase) and negative control (sterile distilled water) were done by paired t-test analysis; clot lysis $\%$ is represented as mean \pm S.D. and $\mathrm{p}$ values of Herbal preparation (Argyria captiformis) was $<0.05$; which was considered as significant.

Table 4. Phytochemical constituents identified in the ethanolic plant extracts of Argyria Captiformis.

\begin{tabular}{ll}
\hline Test for & Ethanolic extract of Argyria captiformis. \\
\hline Tannins & $(+\mathrm{ve})$ \\
Phlobatannins & $(-\mathrm{ve})$ \\
Terpenoids & $(-\mathrm{ve})$ \\
Glycosides & $(+\mathrm{ve})$ \\
Steroids & $(-\mathrm{ve})$ \\
Alkaloids & $(-\mathrm{ve})$ \\
Carbohydrates & $(-\mathrm{ve})$ \\
Saponins & $(+\mathrm{ve})$ \\
Phytosterols & $(+\mathrm{ve})$ \\
Phenols & $(-\mathrm{ve})$ \\
Flavonoids & $(+\mathrm{ve})$ \\
Protein \& Amino acid & $(-\mathrm{ve})$ \\
Antraquinone & $(-\mathrm{ve})$ \\
Cardiac glycosides & $(+\mathrm{ve})$ \\
\hline
\end{tabular}

\section{Discussion}

This study examined some neuropharmacological effects of $A$. captiformis and established that it has anxiolytic and Antidepressant-like activities. The EPM is one of the most widely validated tests and is highly sensitive to the influence of both anxiolytic and anxiogenic drugs acting at the gamma amino butyric acid type A (GABAA) - benzodiazepine complex ${ }^{[29]}$.

In EPM, normal mice will normally prefer to spend much of their allotted time in the closed arms. This preference appears to reflect an aversion towards open arms that is generated by the fears of the open spaces. Drug like diazepam that increases open arm exploration are considered as anxiolytic and the reverse holds true for anxiogenics ${ }^{[30]}$. In this study, we observed that the administration of dose (400 $\mathrm{mg} / \mathrm{kg}$ body weight) of ethanolic extract of $A$. captiformis induced an anxiolytic-like effect in mice, as it increased open arm entries and the time spent in the open arms of the EPM when compared to the control animals.

Earlier reports showed a significant decrease in the locomotor score for diazepam when compared to the control 
animals. Locomotor activity is considered as an index of alertness and a decrease in that indicates sedative effects ${ }^{[31]}$.The doses ( $400 \mathrm{mg} / \mathrm{kg}$ body weight) of the $A$. captiformis showed a decrease in the locomotor score and produced a significant increase in the hypnotic effect induced by the thiopental sodium, thus suggesting a profound sedative activity. Thiopental is basically a hypnotic agent, given at appropriate dose, induced hypnosis by potentiating GABA mediated post synaptic inhibition through allosteric modification of GABAA receptors. Substances which possess CNS depressant activity either decrease the time for onset of sleep or prolong the duration of sleep or both ${ }^{[32,33]}$. In addition, the study on locomotor activity, as measured by hole cross and open field tests, showed that dose of ethanol extract from the leaves of $A$. captiformis decreased the frequency and the amplitude of movements.

The method employed for this assay is considered as a very sensitive way to detect agents with CNS depressant activity ${ }^{[34]}$. The sedative effect recorded here may be related to an interaction with benzodiazepines and related compounds that bind to receptors in the CNS and have already been identified in certain plant extracts. Phytochemical analysis of the plant extract reveals that $A$. captiformis contains glycosides, cardiac-glycosides, flavonoids, tannins, Phytosterols and saponins. Many flavonoids and neuro-active steroids were found to be ligands for the GABAA receptors in the CNS; which led to the hypothesis that they act as benzodiazepine-like molecules ${ }^{[35-}$

37]. This is supported by the present study on the behavioral effects in animal models of anxiety and sedation.

It may possible that the mechanism of anxiolytic action of A. captiformis ethanol extract could be due to the binding of any of the phyto-constituents to the GABAA-BZD complex. In support of this, it has been found that flavones bind with high affinity BZD site of the GABAA receptor ${ }^{[38]}$.

The locomotor activity is a measure of the level of excitability of the CNS and sedation resulting from depression of the central nervous system ${ }^{[39]}$. The result indicated that the extract significantly decreased the locomotor activity as shown by the results of the open field and hole cross tests. The results were also statistically significant. Therefore, the use of $A$. captiformis in folkloric medicine may be due to its CNS action validated by our findings. However, further investigation is necessary to determine the exact phyto-constituents and mechanism of action that are responsible for the biological activities of the ethanol extract of $A$. captiformis.

There are several thrombolytic drugs obtained from various sources. Some are modified further with the use of recombinant technology in order to make these thrombolytic drugs more site specific and effective. Side effects related to these drugs have been reported that lead to further complications. Sometimes the patients die due to bleeding and embolism ${ }^{[40-42]}$.

In the clot lysis study, the \% of clot lysis by positive \& negative controls differs significantly as the $\mathrm{p}$ value was < 0.0001. The comparison among the extract of Argyria captiformis\& Argyria captiformis in combination with Streptokinase, water (negative control) \& streptokinase (positive control) concluded by the significant thrombolytic activity of the ethanolic extract of Argyria captiformis leaves.

The preliminary Phytochemical screening of different extracts was done to ascertain the Presence of bioactive components. The Presence of Tannins, Glycosides, Saponins, Phytosterols, Flavonoids, and Cardiac glycosides was determined.

\section{Conclusion}

From this experiment, it can be concluded that Argyria captiformis has got the very good potential as a candidate for future thrombolytic agent and also interested to find out the active component(s) responsible for anxiolytic effect of this plant This is only a preliminary study and to make final comment the extract should thoroughly investigated phytochemically and pharmacologically to exploit their medicinal and pharmaceutical potentialities.

\section{Contest}

All persons in this study were willingly volunteered and no one was forced to do this. Before withdrawal of blood sample from them they were alert about the procedure. We also maintained and ensured the personal hygiene and safety procedure before starting with them, thus they feel safe with us. So there is no chance of violation with patient consent or ethical rules in case of using human volunteers.

\section{Acknowledgments}

Authors would like to thank Department of Pharmacy, International Islamic University Chittagong for conducting this research work. Special thanks to Taxonomist and Associate professor, Dr. Sheikh Bokhtear Uddin, Department of Botany, University of Chittagong, for identification of this plant and the blood donors for thrombolytic purpose.

\section{References}

[1] Buller R, Legrand V. Novel treatments for anxiety and depression: hurdles in bringing them to the market. Drug Discovery Today 2001; 6: 1220-1230.

[2] Yadav AV, Kawale LA, Nade VS. Effect of Morus Alba L. (mulberry) leaves on anxiety in mice. Indian J Pharmacol 2008; 40: 32-36.

[3] Titov N, Andrews G, Kemp A, Robinson E. Characteristics of adults with anxiety or depression treated at an internet clinic: comparison with a national survey and an outpatient clinic. PLOS ONE 2010; 5(5): e10885.

[4] Woode E, Abotsi WK, Mensah AY. Anxiolytic-and antidepressant-like effects of an ethanolic extract of the aerial parts of Hilleria latifolia (Lam.) H. Walt. in mice. J Nat Pharm 2011; 2: 62-71. 
[5] Rabbani M, Sajjadi SE, Mohammadi A. Evaluation of the anxiolytic effect of Nepeta persica Boiss. In mice. EvidBased Complement Alternat Med 2008; 5(2): 181-186.

[6] Raihan MO, Habib MR, Brishti A, Rahman MM. Sedative and anxiolytic effects of the methanolic extract of Leea indica Burm.

[7] Rahman H, Elumalai A, Eswaraiah MC, Bardalai D. Evaluation of anxiolytic activity of ethanolic extract of Pisonia grandis $\mathrm{R} . \mathrm{Br}$

[8] Newman M, Lhuillier A, Poulsen AD. Checklist of the Zingiberaceae of Malesia. Blumea Suppl 2004; 16: 166.

[9] Wu DL. Flora of China.Vol.16, Fascicle 2. Beijing: Science Press; 1981, p. 67-106.

[10] Thrombus.2011.Thrombus.[ONLINEAvailableat: http://adam.about.net/encyclopedia/Thrombus.htm. [Accessed 21 August 2011].

[11] D.R. P.N. Bennett; Clinical Pharmacology: Seventh Edition 1992: Page 483

[12] Nicolini FA, Nichols WW, Mehta JL, Saldeen TG, Schofield R, Ross M, Player DW, Pohl GB, Mattsson C. Sustained reflow in dogs with coronary thrombosis with K2P, a novel mutant of tissue plasminogen activator. $\mathrm{J} \mathrm{Am}$ Coll Cardiol. 1992; 20:228-235.

[13] Adams DS, Griffin LA, Nachajko WR, Reddy VB, Wei CM. A synthetic DNA Encoding a modified human urokinase resistant to inhibition by serum plasminogen activator inhibitor. J Biol Chem. 1991; 266:8476-8482.

[14] Lijnen HR, Vanhoef B, DeCock F, Okada K, Ueshima S, Matsuo O. On the mechanism of fibrin-specific plasminogen activation by staphylokinase. $J$ Biol Chem. 1991; 266:1182611832.

[15] Marder VJ. Recombinant streptokinase - opportunity for an improved agent. Blood Coagul Fibrinolysis. 1993; 4:1039-1040.

[16] Wu DH, Shi GY, Chuang WJ, Hsu JM, Young KC, Chang CW Coiled coil region of streptokinase gamma-domain is essential for plasminogen activation. J Biol Chem. 2001; 276:15025-15033. doi: 10.1074/jbc.M005935200.

[17] Harborne JB (1998). Phytochemical Methods. Chapman and Hall, London.

[18] Giuseppina Basta, Cristiana Lupi, Guido Lazzerini, Piero Chiarelli, Antonio L'Abbate, Daniele Rovai: Therapeutic effect of diagnostic ultrasound on enzymatic thrombolysis. An in vitro study on blood of normal subjects and patients with coronary artery disease. Thromb Haemost 2004, 91:1078-1083.

[19] www.Ethnobotanical Database of Bangladesh (EDB) 3.1 Plants of Bangladesh

[20] Rahman, M.A., Uddin, S.B., Wilcock, C.C., 2007. Medicinal Plants used by Chakma tribe in Hill Tracts districts of Bangladesh. Indian Journal of Traditional Knowledge. 6(3):508-517.

[21] Gupta BD, Dandiya PC, Gupta ML. A psychopharmacological analysis of behavior in rat. Jpn J Pharmacol 1971; 21: 293.

[22] Lister RG. The use of a plus-maze to measure anxiety in the mouse. Psychopharmacology (Berl) 1987; 92: 180-185.

[23] Pellow S, Chopin P, File SE, Briley M. Validation of open: closed arm entries in an elevated plus-maze as a measure of anxiety in the rat. J Neurosci Methods 1985; 14: 149-167.

[24] Ferrini R, Miragoli G, Taccardi B. Neuro-pharmacological studies on SB 5833, a new psychotherapeutic agent of the benzodiazepine class. Arzneim-Forsch (Drug Res) 1974; 24: 2029-2032.

[25] Takagi K, Watanabe M, Saito H. Studies on the spontaneous movement of animals by the hole cross test; effect of 2dimethylaminoethanol and its acyl esters on the central nervous system. Jpn J Pharmacol 1971; 21: 797-810.

[26] Sweta Prasad, Rajpal Singh Kashyap, Jayant Y Deopujari, Hemant J Purohit, Girdhar M Taori and Hatim F Daginawala. Effect of Fagonia Arabica (Dhamasa) on in vitro thrombolysis, BMC Complementary and Alternative Medicine 2007, 7:36 doi: $10.1186 / 1472-6882-7-36$

[27] Prashant Tiwari, Bimlesh Kumar,Mandeep Kaur,Gurpreet Kaur,Harleen Kaur Phytochemical screening and Extraction,2011.International Pharmaceutica Sciencia journal, vol.1,Issue 1 (2011)

[28] http://www.ukessays.co.uk/essays/biology/phytochemicalanalysis.php

[29] Dhonnchadha BAN, Bourin M, Hascoet M. Anxiolytic-like effects of 5-HT2 ligands on three mouse models of anxiety. Behav Brain Res 2011; 140: 203-214.

[30] Subramanian N, Jothimanivannan C, Kumar RS, Kameshwaran S. Evaluation of anti-anxiety activity of Justicia gendarussa burm. Pharmacologia 2013; 4(5): 404407.

[31] Thakur VD, Mengi SA. Neuropharmacological profile of Eclipta alba (Linn.) Hassk. J Ethnopharmacol 2005; 102(1): 23-31.

[32] Raquibul Hasan SM, Hossain MM, Akter R, Jamila M, Mazumder EHM, Rahman S. Sedative and anxiolytic effects of different fractions of the Commelina benghalensis Linn. Drug Discov Ther 2009; 3: 221-227.

[33] Sen AK, Bose S, Dutta SK. Comparative evaluation of CNS depressant activity of the flavonoid fractions from the fresh leaves and flowers of Ixora coccinea Linn. J Pharma Sci Tech 2011; 1(1): 54-56.

[34] Hossain MM, Biva IJ, Jahangir R, Vhuiyan MMI. Central nervous system depressant and analgesic activity of Aphanamixis polystachya (Wall.) parker leaf extract in mice. Afr J Pharm Pharmacol 2009; 3(5): 282-286.

[35] Fernández SP, Wasowski C, Loscalzo LM, Granger RE, Johnston GA, Paladini AC, et al. Central nervous system depressant action of flavonoid glycosides. Eur J Pharmacol 2006; 539: 168-176.

[36] Jäger AK, Saaby L. Flavonoids and the CNS. Molecules 2011; 16: 1471-1485.

[37] Johnston GA. GABA (A) receptor channel pharmacology. Curr Pharm Des 2005; 11: 1867-1885.

[38] Hanrahan JR, Chebib M, Johnston GAR. Flavonoid modulation of GABAA receptors. Br $J$ Pharmacol 2011; 163(2): 234-245. 
[39] Thirupathy KP, Tulshkar A, Vijaya C. Neuropharmacological activity of Lippia nodiflora Linn. Pharmacognosy Res 2011; 3(3): 194-200.

[40] Boudjeltia KZ, Cauchie P, Remacle C, Guillaume M, Brohee D, Hubert JL, Vanhaeverbeek M: A new device for measurement of fibrin clot lysis: application to the Euglobulin Clot Lysis Time. BMC Biotechnology 2002, 2:8.

[41] Greenberg RK, Ouriel K, Srivastava S, Shortell C, Ivancev K,
Waldman D, Illig K, Green R: Mechanical versus Chemical Thrombolysis: An In Vitro Differentiation of Thrombolytic Mechanisms. Journal of Vascular and Interventional Radiology 2000, 11:199-205.

[42] Erzsebet Komorowicz, Krasimir Kolev, Istvan Lerant, Raymund Machovich: Flow Rate- Modulated Dissolution of Fibrin with Clot-Embedded and Circulating Proteases. Circulation Research 1998, 82:1102-1108. 